\title{
INFÂNCIAS POR ESCRITO: CARTAS DE ESCOLARES EM UM SUPLEMENTO INFANTIL CATARINENSE (1972-1987)
}

\author{
Luciana Mara Espíndola Santos* \\ lattes.cnpq.br/5048852591657850 \\ Maria Teresa Santos Cunha** \\ lattes.cnpq.br/1895532605964830
}

\begin{abstract}
Resumo: Este artigo busca discutir alguns aspectos que envolveram a produção de $O$ Estadinho, suplemento infantil dominical encartado pelo jornal O Estado (19152009), em Santa Catarina e que circulou entre 1972 e 1987. O estudo pretende analisar esse suplemento infantil ao longo de seus quinze anos de existência, evidenciando distintos modos de perceber e construir a escrita das infâncias ressaltando as cartas publicadas de leitores. As cartas foram aqui analisadas, na perspectiva da cultura escrita, onde se valorizava aspectos relacionados as motivações dos escreventes, as redes de sociabilidade envolvidas, as políticas editorias do suplemento. Cartas trocadas entre o suplemento e seus leitores e publicadas nesse impresso testemunham de como a infância vivida por aquelas crianças, que se correspondiam com $O$ Estadinho, estava permeada por elementos relacionados à escolarização e a uma relação afetiva com o próprio impresso infantil.
\end{abstract}

Palavras-chaves: $O$ Estadinho; Infâncias; Cartas infantis; Escolarização.

\section{WRITTEN CHILDHOOD: LETTERS FROM SCHOOLCHILDREN IN AN INFANT SUPPLEMENT FROM SANTA CATARINA (1972-1987)}

\begin{abstract}
This article aims to discuss some aspects that involved the production of $O$ Estadinho, a Sunday supplement for children published by the newspaper $O$ Estado (1915-2009) in Santa Catarina and circulated between 1972 and 1987. The study intends to analyze this child supplement throughout its Fifteen years of existence, evidencing different ways of perceiving and constructing childhood writing highlighting the letters published by readers. The letters were analyzed from the point of view of the written culture, where aspects related to the motivations of the clerks, the networks of sociability involved, and the publishing policies of the supplement were val-
\end{abstract}

\footnotetext{
* Doutoranda em Educação pela Universidade do Estado de Santa Catarina, UDESC (Brasil). Contato: luciana espin@hotmail.com.

** Doutora em Educação. Docente na Universidade do Estado de Santa Catarina, UDESC (Brasil). Contato: mariatsc@gmail.com.
} 
ued. Letters exchanged between the supplement and its readers and published in this form testify to how the childhood lived by those children, who corresponded with $\mathrm{O}$ Estadinho, was permeated by elements related to schooling and to an affective relationship with the child's own print.

Keywords: $O$ Estadinho; Childhood; Children's letters; Schooling.

$$
* \quad * \quad *
$$

\section{CARTAS}

Olá amigos do ESTADINHO! É com imenso prazer que venho mais uma vez mandar desenhos pra vocês. Desta vez uma novidade. A capa do ESTADINHO! Mando um desenho para ser colocado na primeira página do jornal. Se for do interesse de vocês publicarem o desenho, é bom colocarem embaixo do nome ESTADINHO.

Se agradar o desenho, mais tarde mandarei outros. Quanto às tiras, continuarei a mandar semanalmente. Agradeço a valiosa ajuda que esse jornal vem dando a todos (inclusive eu) que estão começando a produzir estórias em quadrinhos. Tomara que continue sempre assim.

Do sempre companheiro, Daniel Moraes, Orleãs/SC. (O ESTADINHO, 1986, p. 2).

Oi O ESTADINHO. Estou mandando as brincadeiras da semana passada, pois gostei muito delas. Gostaria também que o jornalzinho fizesse uma reportagem sobre as raças dos cães, porque tenho um cão da raça Collie e seria muito interessante. Queria dizer que o jornalzinho está tão bom quanto sempre foi. Um abraço e um beijão para todos aí. Jussara Regina Eckel, 10 anos. Florianópolis/SC. (O ESTADINHO, 1987, p.2).

Querido ESTADINHO. Eu estou escrevendo de novo para vocês com mais colaborações. Só que agora são minhas e do meu irmão. Meu nome é Francine Simas, 11 anos. E do meu irmão é Maikon Simas, 5 anos. Obrigada por ter publicado meus desenhos e pela bela atenção. Ah! eu já ia me esquecendo. Eu mando muitos elogios para vocês e eu adoro os quadrinhos do DIGO. Sugestão: Porque vocês não aumentam mais o jornal? (O ESTADINHO, 1987, p. 2). 
Daniel, Jussara e Francine, crianças catarinenses, leitoras e consumidoras de $O$ Estadinho, representam por meio de suas cartas, uma relação de confiança, de parceria e mesmo de carinho entre leitores e esse impresso infantil, que circulou por aproximadamente 15 anos, entre 1972 e 1987, sempre encartado aos domingos pelo jornal $O$ Estado. Nessa trajetória o impresso foi produzindo uma sensibilidade (CUNHA, 2011) a favor da infância, contribuindo para a educação dos gostos, criando e incentivando hábitos não só de ler jornal, mas também de expressar-se e comunicar-se com outros leitores. De uma forma ou de outra, colocou meninos e meninas como atores sociais, sobretudo, a partir da década de 1980.

Nas cartas expostas anteriormente, é possível perceber a possibilidade de uma participação ativa das crianças nesses veículos de comunicação de massa, ainda que por meio de um suplemento infantil, mas que vinha encartado - como já mencionado - em um impresso de grande circulação em Santa Catarina. Crianças leitoras que sugerem pautas para o suplemento infantil, que se aventuraram em atividades típicas dos adultos, como "fazer as estórinhas", dando a ver um certo protagonismo infantil por meio da escrita e de desenhos enviados ao $O$ Estadinho.

O presente estudo pretende analisar esse suplemento infantil ao longo de seus 15 anos de existência, evidenciando distintos modos de perceber e construir, por escrito, as infâncias. Como $O$ Estadinho foi se popularizando, por onde circulou? O que o suplemento priorizava em seu espaço? Quem eram seus leitores e que escreviam nas cartas enviadas? Como interagiam? E o que fez $O$ Estadinho desaparecer quando parecia viver o seu melhor momento? Estas e outras perguntas guiam a análise aqui empreendida. Com esta expectativa traçou-se uma trajetória de $O$ Estadinho, por meio das cartas - um espaço destinado aos leitores -, que ganhou fôlego, sobretudo, nos últimos anos de vida do suplemento. As cartas foram aqui analisadas, na perspectiva da cultura escrita, seguindo a abordagem que vem sendo realizada pelo grupo liderado por Antonio Castillo Gómez e Veronica Sierra Blas (2008, p. 19) em uma coletânea de estudos intitulada "Mis primeros pasos. Alfabetización, escuela y usos 
cotidianos de la escritura (siglos $X I X$ y $X X$ )”. Para eles, História da Cultura Escrita é o estudo da produção, difusão, uso e conservação dos objetos escritos (...) para isso busca alianças com quantos saberes, como os advindos da História da Educação Escolarizada, que têm como seu objeto o estudo da escrita em suas várias modalidades.

Analisaram-se, também, aspectos relacionados às motivações dos escreventes, às redes de sociabilidade envolvidas e às políticas editorias do suplemento. Temos a clareza de que tão importante quanto estudar o sistema gráfico é também preocupar-se ou (...) interrogarse principalmente por sus distintas funciones y las consiguientes prácticas materiales. Siempre en referencia constante a la sociedade y teniendo em cuenta que ésta la integram hombres y mujeres alfabetizados y analfabetos. (CASTILLO, 2005, p. 19).

O material analisado compõe-se de 128 edições do suplemento $O$ Estadinho, arquivadas no setor de obras raras da Biblioteca Pública de Santa Catarina, e também em acervos pessoais.

Surgido no ano emblemático de 1972, em meio a um período ditatorial em que o país vivia aterrorizado pela falta de liberdade de expressão, a repressão aos meios de comunicação, perseguições etc. (SCHWARCZ; STARLING, 2015), O Estadinho emerge como um produto dedicado ao público infantil (mas não somente a ele), evidenciando uma sensibilidade a favor da infância. Porém, não se pode, a menos no Brasil, atribuir a esse novo produto cultural somente a uma valorização da infância. Outros fatores de ordem econômica, relacionados à tecnologia e à criação de mercados consumidores, inclusive com auxílio da televisão (SERPA, 2011; HAMBURGER, 1998) agiram de forma determinante para que tais produtos pudessem reverberar a ideia e os discursos que o governo militar fazia circular na época. Sobretudo relacionados ao progresso e futuro da nação, que teria sido trazido pelas mãos desse governo (SERPA, 2011; 2004).

Já as causas para o encerramento da publicação de $O$ Estadinho, pouco se conhece, e, na verdade, se especula. O que se pode afirmar é que sua trajetória chegou ao fim no momento em que o suplemento mais se dedicou à infância e à busca de uma infância mais crítica, menos infanti- 
lizada. Um momento em que a participação dos leitores se dava por várias frentes (reportagens, envio de histórias, quadrinhos, etc.), sendo as cartas, um bonito registro de uma comunicação que servia como elo de compromisso, carinho, respeito e sem infantilização entre $O$ Estadinho e seus leitores.

Nesse texto serão apresentados alguns aspectos desse suplemento infantil, abordando o espaço destinado aos leitores, por meio de cartas, compreendendo que as cartas publicadas na seção Cartas de $O$ Estadinho foram em sua maioria de autoria infantil, entretanto, é possível que pais, professores e mesmo outros adultos tenham colaborado com a escrita de tais cartas. Diferente de cartas escritas por adultos, as missivas infantis possivelmente passavam pelo olhar de uma pessoa mais experiente, seja para corrigi-las, censura-las ou mesmo incluir nelas alguma informação. Na edição de 23 de março de 1986, o Editorial atesta tal fato.

E parece que os poetas começaram mesmo a aparecer pelo $\mathrm{O}$ Estadinho. Recebemos esta semana da professora Diva Zandomênego poemas feitos pelos seus alunos da $8^{\mathrm{a}}$. série do Colégio Silveira de Souza. Taí uma coisa que todas as professoras e professores podiam fazer, cada vez mais poesia no nosso jornal. (O ESTADINHO, 1986, p. 2).

Cartas trocadas entre o suplemento e seus leitores e publicadas nesse impresso testemunham como a infância vivida por aquelas crianças que se correspondiam com $O$ Estadinho, estava permeada por elementos relacionados à escolarização e a uma relação afetiva com o mesmo.

$\mathrm{Na}$ esteira do trabalho realizado pela historiadora espanhola Verônica Sierra Blas (2003), existem recomendações e tipologias epistolares propostas tais como: suporte, data, vocativo, estilos, formas de despedida para a escrita de cartas. Tais recomendações textuais, historicamente construídas, apresentam prescrições/receitas para a prática da correspondência - as regras do bom tom da escrita epistolar - que se pretendia difundir na educação escolarizada. 


\section{Espaço destinado aos leitores}

A primeira comunicação com o suplemento, certamente não foi pela escrita. Os olhos foram sem dúvida (salvo os casos de falta de visão) os primeiros a estabelecer com $O$ Estadinho alguma relação. Ler, pintar, desenhar, caçar as palavras da seção divertimentos permitia uma interação direta com o suplemento, que, pouco a pouco foi cedendo as páginas de seu impresso para publicação de criações de seus leitores.

De concurso de desenhos, passando por redações e pequenos textos homenageando soldados, aviadores e jornalistas, comuns nos primeiros anos do suplemento, $O$ Estadinho a partir de 1984 passa a investir em outras formas de interação com seus leitores. Seções inteiras dedicadas à participação de leitores, matérias construídas integralmente por "repórteres mirins" e uma seção praticamente aberta de troca de correspondências entre o suplemento e seus leitores. Intenções que circularam em outros países, como publicou o periódico infantil Primeras Noticias, da Espanha:

(...) dejáis de ser lectores para convertiros en informadores, haciendo reportajes, dibujos, fotografías o lo que más os guste... También podéis hacer sugerencias sobre la marcha de la revista; preguntar cualquier cosa; conectar com chicos y chicas de España para cambiar sellos (...). (Primeras Noticias, 1978 apud CHIVELET, 2009, p. 284).

Novos espaços em construção. O leitor passa a ser colaborador e o elemento que em grande parte favorece isso é a carta. Quase em desuso nos dias de hoje, a carta já foi grande protagonista na conversação de namorados, na cobrança de dívidas, no aviso da conquista de um cargo público e na comunicação com editores de jornais e revistas. E foi por meio dela que editores e leitores registraram em $O$ Estadinho, pequenos fragmentos de infâncias e de ser criança entre os anos de 1972 a 1987, que, como sugere Roger Chartier (1990, p. 16-17) apresentam como "uma realidade é construída, pensada e dada a ler”. 


\section{Papel e caneta na mão, escrever para $O$ Estadinho}

A primeira vez que o suplemento catarinense se usou das cartas para estabelecer uma comunicação com seus leitores foi no ano de 1972, já no seu final, exatamente na edição de número 31, de 17 de dezembro. $\mathrm{O}$ texto, que ocupou meia página do suplemento, sugere a criação da seção como resposta a uma demanda dos próprios leitores, que estariam enviando cartas aos editores do suplemento. Seções de cartas com este propósito eram bastante comuns em jornais e revistas e o próprio jornal $O$ Estado mantinha diariamente uma coluna em que publicava cartas de seus leitores.

Nos impressos infantis a carta como meio de comunicação entre leitores e editores não foi exclusividade do periódico catarinense. Outros materiais desse gênero já usavam das missivas para estabelecer tal contato, e mais, criar uma espécie de elo entre leitores e o suplemento, sobretudo, no sentido de permitir que os próprios leitores, de alguma forma, contribuíssem para a confecção de "pautas" para o jornal, como especifica o texto da seção "Cartas" de $O$ Estadinho, e também as de outros suplementos que circularam no Brasil e em outros países em períodos semelhantes, como, a Folhinha de São Paulo, O Tico-Tico, El Cambalache (Espanha), Zipizape (Espanha), Mini Ya (Espanha). É importante ressaltar que publicações de textos, desenhos e mesmo fotos de crianças também cativavam os olhos adultos, pois esses impressos antes de chegarem às mãos infantis, passavam em boa medida, “(...) pelo crivo e aceitação dos familiares" (ALENCAR, 2015, p. 117).

O suplemento da Folha de São Paulo, em muitas edições, publicava desenhos e historinhas de seus leitores, até mesmo incentivava a troca de correspondência entre eles por meio de um "Clube de correspondência", entretanto, uma seção destinada à publicação de cartas dos leitores não foi observada de modo sistemático e regular nas décadas de 1970 e 1980. Nem mesmo o suplemento catarinense conseguira a partir de finais de 1972 manter a seção conforme descreveu em seu editorial, somente nos 
anos de 1986 e 1987 é que $O$ Estadinho consegue estabelecer com certa regularidade por meio das cartas uma comunicação com seus leitores.

A seção que publicou muitas cartas e também respostas a seus leitores, "deu a ver" que mesmo sendo um suplemento pensado para crianças, adultos também liam e contribuíam com $O$ Estadinho. Há indícios

Figura 1 - Capa de O Estadinho. Fonte:

Acervo Biblioteca Pública de Santa Catarina.

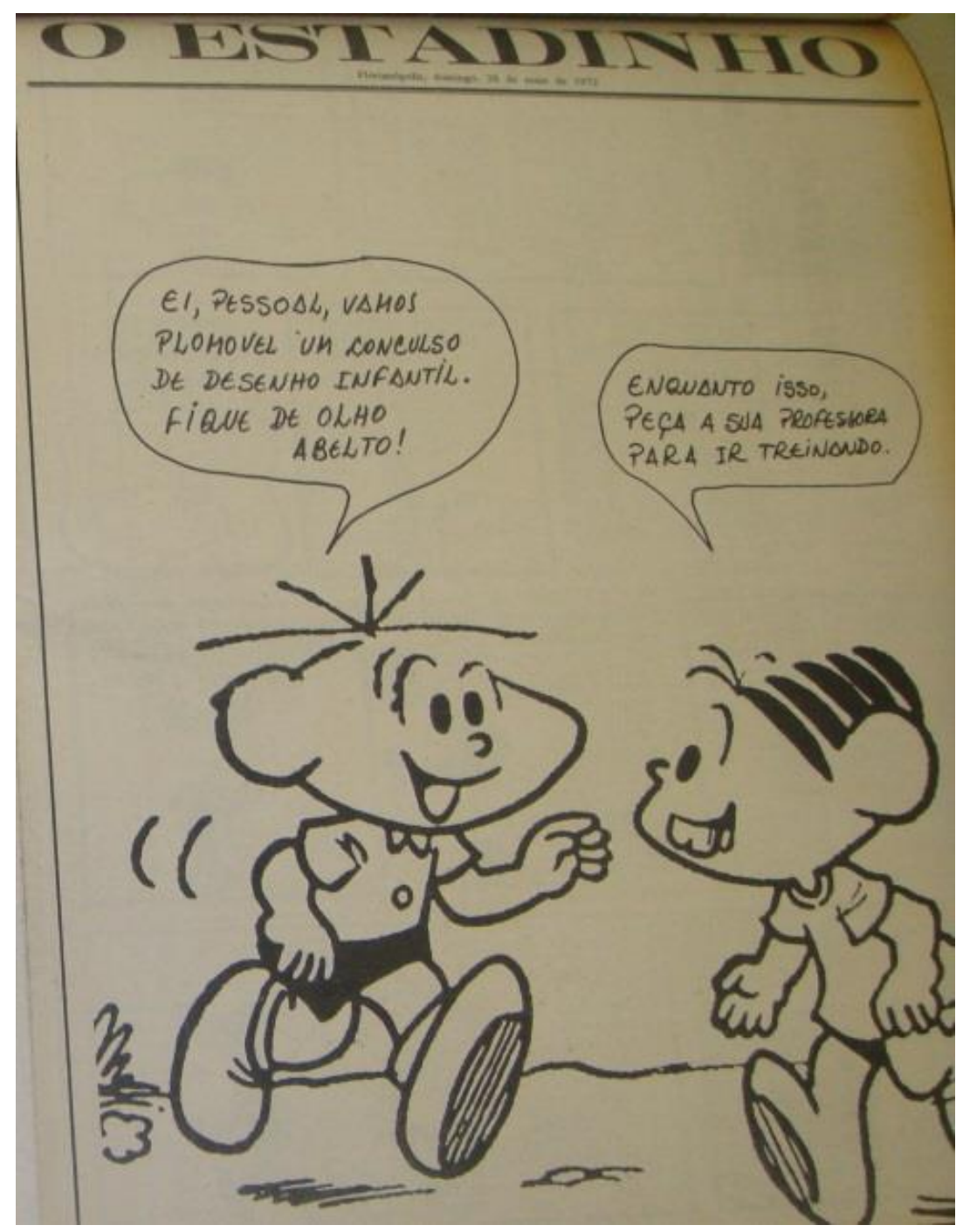

não só na seção de cartas, mas no próprio editorial do suplemento e nas chamadas para os concursos promovidos pelo suplemento, que incentivava a seus leitores buscar ajuda de suas professoras.

A capa de 28 de maio de 1972 não foi o único momento em que o suplemento mostrou certo diálogo com público além do infantil, a relação estabelecida com seus leitores levava em consideração a possibilidade de $O$ Estadinho ganhar também a atenção dos adultos e não só como apreciadores da seção de fotos de crianças ${ }^{1}$, mas como participante na produção do suplemento, como se percebe na carta de César Augusto Sarkis no suplemento de 30/11/1986.

\footnotetext{
${ }^{1}$ Durante o período em que circulou, foram constantes as seções com fotos de crianças, uma espécie de "coluna social” infantil.
} 
Senhor Editor,

Fico feliz em saber que a cada dia aumenta a participação das crianças neste querido jornalzinho. Continuem sempre assim, pois o caminho futuro chama-se criança. A Yasminy Michelle manda um beijinho carinhoso.

César Augusto Sarkis. (O ESTADINHO, 1986, p. 2).

$O$ Estadinho deixa evidências de que mesmo sendo um material para crianças, por ser encartado por um jornal "adulto", possivelmente a primeira mão a alcançar o suplemento era a de um adulto. Ainda que esse fato possa não dizer muita coisa. As cartas escritas por César Augusto Sarkis permitem pensar que a atitude desse pai o fazia leitor de $O$ Estadinho, pois ele opinava sobre o suplemento, além de demonstrar acompanhar sua evolução quanto à participação das crianças no impresso. $\mathrm{O}$ suplemento de 11/01/1987 também trouxe na seção cartas uma mensagem de César Augusto, que dizia:

Estou enviando-lhe uma pequena, mas sincera homenagem a vocês e desejando-lhe Feliz Natal em nome da Yasminy e de todas as crianças, por toda dedicação e carinho que vocês dedicam. Feliz Natal. Cesár Augusto Sarkis.

(O ESTADINHO, 1987, p. 2).

Em resposta, o suplemento agradeceu dizendo: "Muito obrigado pelo poema que mandou pra gente, César. E desejamos um feliz Ano Novo para todos que acompanham O Estadinho" (O ESTADINHO, 11/01/1987, p. 2). Mais do que escrever para a seção cartas, alguns leitores já mais "crescidinhos" enviavam suas colaborações literárias. Outro caso foi o da professora Geraldina Burin, que escreveu:

Prezado editor. Ontem, por brincadeira continuei a estória d'O ESTADINHO (publicada na capa). Estou remetendo-a, se quiserem aproveitá-la, tudo bem. Sempre somos um pouco crianças e isso é gostoso. Um abração e muito obrigada. Professora Geraldina Burin. Florianópolis, SC.

(O ESTADINHO, 1986, p. 2).

O Estadinho manifestou contentamento pela participação da professora, dizendo: "Olha aí pessoal, até gente grande está participando. A 
estória da professora Geraldina é um barato e logo publicaremos" (O ESTADINHO, 07/12/1986, p. 2).

Além das cartas enviadas pelos próprios adultos, em algumas correspondências escritas pelas crianças, pode-se perceber que o adulto também lia o suplemento. A carta escrita por Raquel de Albuquerque Ramos, de 10 anos, apresenta elemento que atestam um interesse de adultos nesse material e também incentivo do adulto a participação de crianças de seu convívio.

Aos amigos d'O ESTADINHO:

Papai nasceu em Lages, mamãe também. Tenho avós em Lages e em Florianópolis. Muitos tios e primos também. Eu amo Santa Catarina e passo férias de verão aí e é a maior felicidade.

Eu nasci em Brasília e moro em Brasília. Eu gosto de morar aqui. Tenho 10 anos, uma irmã de 13 - Fernanda - e estou na $5^{\mathrm{a}}$ série. Sou boa aluna e adoro ler e escrever. Vovô manda $\mathrm{O}$ ESTADINHO toda semana e quando papai consegue ele compra O ESTADO aqui em Brasília.

Eu adoro O ESTADINHO. Está cada vez melhor, pois não coloca só quadrinhos e coisas para crianças bem pequenas como em outros jornais. Eu até já levei para o quadro mural de meu colégio.

Essa semana eu fiz esta poesia na aula de português (O poema está na página 7). A professora deu tema livre. Ela gostou tanto que mandou para papai ler. Meu pai é jornalista e professor da UNB (Universidade Nacional de Brasília). Daí ele me deu essa ideia: - "Se você mandar para O ESTADINHO e eles publicarem, todo mundo vai ler".

É uma poesia chamada: Já virou beco sem saída. Eu fiz dia 11. Sabem que acabou de sair um Cruzado 3 ? Plano econômico. Interesse pelos temas "adultos". Eu escutei a notícia na TV e não sei como vai ser. Um beijo grande da amiguinha Raquel de Albuquerque Ramos. Brasília - DF. (O ESTADINHO, p. 2).

A missiva da menina de 10 anos possui elementos que além de sugerirem leitura adulta, acabam por mostrar o alcance do suplemento, que não se restringia apenas a crianças catarinenses e filhos de pais com boas condições financeiras. Leitores e "colaboradores" de $O$ Estadinho espalhavam-se pelo país e fora dele também², o que não restringia sua circu-

${ }^{2}$ No suplemento de 4/11/1979 uma nota evidencia a circulação do suplemento no RS. A edição de 7/12/1986, menciona a leitura do suplemento por crianças argentinas. 
lação ao estado catarinense. Assim na seção cartas de 7/12/1986, o menino Sérgio Sebastião Kutscher de Oliveira, de 11 anos, relata: "Meus amiguinhos argentinos de nossa vizinha cidade de Bernardo Irigoyen 3 também gostam de ler O ESTADINHO” [sic.] (O ESTADINHO, 07/12/1986, p. 2).

Leitores de outros estados, leitores adultos, leitores cuja língua materna não era o Português, foram aparecendo e crescendo à medida que o próprio suplemento também emergia como um projeto editorial mais voltado à infância. O Estadinho, em seus últimos anos, e, sobretudo, com a entrada da LADESC 4 na coordenação do material, amplia sua comunicação com seus leitores o que de certa forma, também reverbera em um aumento de circulação. Voltado inicialmente ao entretenimento de crianças cujos pais assinavam ou compravam o jornal de domingo, O Estadinho alcança leitores por outras vias. A escola, por exemplo, fez parte de $O$ Estadinho, oportunizando que crianças sem acesso ao suplemento pudessem conhecê-lo, como ocorreu nas edições de 01/12/1974 e 12/04/1987, em que crianças do Colégio de Aplicação do Instituto Estadual de Educação, respectivamente, maior colégio público de Santa Catarina, puderam conhecer e escrever para o suplemento.

Crianças vinculadas a alguns projetos sociais do Pró-Criança5, igualmente contribuíram com o suplemento infantil. Dentre os colaboradores de $O$ Estadinho estavam professoras, como Maria Schillikman (Ica), que por meio do Projeto Gaivota ${ }^{6}$, proporcionava que crianças atendidas nele tomassem conhecimento do suplemento, bem como participassem da criação de historinhas. Até mesmo o papel que se usava para

3 Bernardo Irigoyen, cidade argentina que faz fronteira com o Brasil pela cidade catarinense de Dionísio Cerqueira.

4 LADESC - Liga de Apoio ao Desenvolvimento Social Catarinense. Tratava-se de uma instituição sem fins lucrativos, normalmente presidida pela $1^{\mathrm{a}}$. Dama do Estado, Angela Amim, com propósito de fomentar o bem-estar social por meio de atividades educacionais e culturais.

5 Pró-Criança foi um projeto social (1982-1986), destinado às crianças catarinenses com intuito cultural, mas que também incentivou as chamadas "creches domiciliares".

6 Projeto Gaivota foi um subprojeto do projeto Pro-Criança, que visava o atendimento de crianças no contra turno escolar, para a realização de atividades artísticas e de expressão. 
embrulhar peixe, permitiu, ainda que remota, a circulação do suplemento, entre crianças cuja condição econômica da família, era bastante restrita. Foi assim que o menino Nelson Coelho7, tomou conhecimento do suplemento catarinense e tornou-se dele leitor, como ele conta fazendo uso de suas recordações8: “(...) eu adorava ler e $O$ Estadinho chegou por acidente, nas compras que o meu pai fazia, (...) vinha como embrulho de peixe (...)" (COELHO, 2016). Nelson foi um leitor que não se encorajou a escrever para o jornal e dizia ter consciência de que aquele produto impresso era pra crianças ricas. Diferente de Nelson, algumas crianças cujas famílias careciam de recursos financeiros por meio dos projetos do Prócriança escreveram para o suplemento, entretanto em seções organizadas pelos colaboradores do suplemento que atuavam neste Programa.

$\mathrm{Na}$ seção cartas, entretanto, as missivas convidam a pensar que embora o suplemento estivesse mais voltado e preocupado com as questões da infância e o alcance da criança como leitor e colaborador, as escritas pertenciam a um grupo mais homogêneo, com interesses, ideias, e até mesmo gostos parecidos. Nos anos em que essa comunicação, via cartas, se estabelece de modo mais efetivo (1985-1987), pode-se verificar que tal homogeneidade se manifestava em relação às cidades dos leitores, idade e motivos que levavam à escrita das cartas.

Mesmo sendo a seção cartas anunciada no ano de 1972, essa coluna torna-se mais frequente a partir de 1985 (embora sejam poucos os suplementos encontrados na década de 1970) sendo o auge da comunicação por essa via no ano de 1987, quando o suplemento supostamente deixa de circular. Das 18 edições acessadas em 1987, apenas uma não publicou

\footnotetext{
7 Nelson Coelho é historiador, professor de história da rede particular de ensino e doutorando do programa de Educação da FAED/UDESC. Nascido em família cujos recursos financeiros eram limitados, a leitura de jornais e revistas não fazia parte do cotidiano do menino que há pouco havia ascendido à escola, entretanto, seus pais percebendo o interesse do filho pelo material trataram de "arrecadar" os suplementos pela vizinhança, já que comprar jornal não estava no orçamento familiar. Mesmo sem possibilidade de comprar o jornal e sem hábito de leitura, $O$ Estadinho chegou às mãos do menino pobre, evidenciando a pluralidade de leitores desse suplemento.

${ }^{8}$ Lembrar o passado não é trazê-lo ao presente. Não tal qual foi, mas recorda-lo ativando e mesclando desejos, intenções, projeções e invenções que carecem de problematização, não para desqualifica-lo, mas para deslindar o que se colore.
} 
a seção cartas, diferente do que ocorrera nos anos anteriores, ainda que a partir de 1985 possam ser encontradas algumas edições em que a seção cartas aparece.

Foram publicadas, nessas 17 edições, 64 cartas de meninos, meninas e adultos, dos quais o suplemento respondeu a 60, na própria coluna do jornal.

Querido ESTADINHO.

Eu estou escrevendo de novo para você com mais colaborações. Só que agora são minhas e do meu irmão. Meu nome é Francine Simas, 11 anos. E do meu irmão é Maikon Simas, 5 anos. Obrigado por ter publicado meus desenhos e pela bela atenção. Ah! Eu já ia me esquecendo. Eu mando muitos elogios para vocês e eu adoro os quadrinhos do Digo. Sugestão: Porque vocês não aumentam mais o jornal?

Nós é que agradecemos por vocês participarem. O ESTADINHO só existe porque vocês existem, certo? O DIGO anda muito convencido ultimamente e agradece o elogio. Quanto a sua sugestão de aumentar o jornal, ela é muito boa. Só que o papel jornal está muito caro. Tchau.

(O ESTADINHO, p. 2)

A carta da menina Francine foi uma dentre as $64^{9}$ publicadas no suplemento infantil no ano de 1987 e dá a ver, em boa medida, como $O$ Estadinho foi, por meio de sua política editorial, estabelecendo naquele que seria seu último ano de circulação, uma comunicação bastante próxima a seus leitores. As palavras de carinho, a forma alegre e descontraída das cartas escritas pelos leitores e também às respostas de $O$ Estadinho ficavam lado a lado. Entretanto, se alguma correspondência trazia críticas ao suplemento, era igualmente respondida.

Assim foram envidas 64 cartas ao suplemento, que respondeu a 60 delas. As respostas tinham um tom de aproximação aos leitores, com o uso de palavras como: "amiguinhos", "abração", "beijo", "gostamos muito”, mas que não se furtavam em responder de modo respeitoso e contundente as missivas enviadas, fosse qual fosse o motivo do envio. Mes-

\footnotetext{
9 Este número refere-se ao acervo dessa pesquisa, que conta com 17 edições do ano de 1987, estima-se que tenham sido publicados neste mesmo ano, mais edições de $O$ Estadinho.
} 
mo críticas foram publicadas e respondidas, como a carta da menina Clarissa Araújo Cassol, de 6 anos.

Assim como Clarissa, a menina Alessandra Chaves PeFigura 2 - Carta de uma leitora de reira, de 10 anos chamou a atenção de $O$ Estadinho reclamando da "falta" de assunto do suplemento. A crítica foi publicada e respondida em um único texto, demostrando certa flexibilidade na montagem e organização da seção, que na maioria das vezes apresentava as cartas ou fragmentos das cartas de seus leitores e logo na sequência, a resposta dos editores.

Responder as cartas, publicar o conteúdo enviado, comprometer-se com as solicitações de seus leitores, acatar as sugestões, reconhecer os próprios limites, foram muitas as respostas e muitas as solicitações de leitores e leitoras que, de posse de papel e caneta, escreveram cartas, selaram e as confiaram para envio ou as enviaram à re$O$ Estadinho. Fonte: Acervo pessoal.

Sr. Fábio, quero mais joguinhos n'O ESTADINHO: Por que vocês só botam dois jogos? Eu não gosto da história do digo e do sapo. São sem graça. Estou mandando desenho para publicar. Também não gosto da história dos ratos e daquela menina Giane. Clarissa Araujo Cassol, 6 anos.

Valeu a bronca, Clarissa. Mas o negócio e o seguinte: As histórias que você não gosta, são justamente aquelas que são pruduzidas peto pessoal aqui da redação. Talvez por isso nāo estejam do nivel das histórias do Aauricio, que faz as da Turma da Mônica. Mas vamos fazer o seguinte: escreva pra cá novamente dando sugestões de outras histórias que você conhece e que goste. Talvez a gente até mude, se outras crianças também quiserem, certo? Entāo as crianças que estão lendo a critica da Clarissa, escrevam pra cá que tentaremos anatisar methor os quadrinhos, falou?

O seu desenho; Clarissa será publicado nessa ediçāo mesmo. Escreva sempre, mesmo que seja para fazer outra bronca. Quanto aos joguinhos, etes têm uma página só pra eles, mas taremos o possivel pra dar mais espaço. dação do suplemento infantil. Pode-se considerar que as cartas enviadas pelas crianças evidenciam processos de escolarização que privilegiavam, ensinavam e até incentivavam as próprias crianças a seguir os protocolos epistolares nesta escrita, tais como: a data, o vocativo, as saudações, a forma de encerrar da missiva, conforme anunciam os trabalhos citados anteriormente. Assim, com base em algumas informações contidas nas cartas pode-se afirmar que as meninas foram as grandes colaboradoras 
de $O$ Estadinho, sendo a faixa etária dos 10 aos 11 anos que mais escreveu. Destaque também para as correspondências de Florianópolis e Itajaí, registradas respectivamente em maior número.

\section{OI ESTADINHO.}

Estou mandando essa carta porque eu li no jornal que vocês pedem para nós leitores escrevermos. Então estou mandando dois desenhos e uma brincadeira para o jornal. E tomara que vocês publiquem logo. E por aqui eu acabo a minha carta. Tchau turma. Meu nome é Francine Simas, tenho 11 anos, Itajaí/SC.

Obrigado por ter mandado seus desenhos. Você vai ter que aguentar na fila, certo? Mas é só acompanhar que um dia ele sai. Participe sempre. Um beijão.

(O ESTADINHO, 1987, p.2).

Figura 3 - Carta de uma leitora de

$O$ Estadinho. Fonte: Acervo pessoal.

\section{$12101 / 86$ " "Estadinho"}

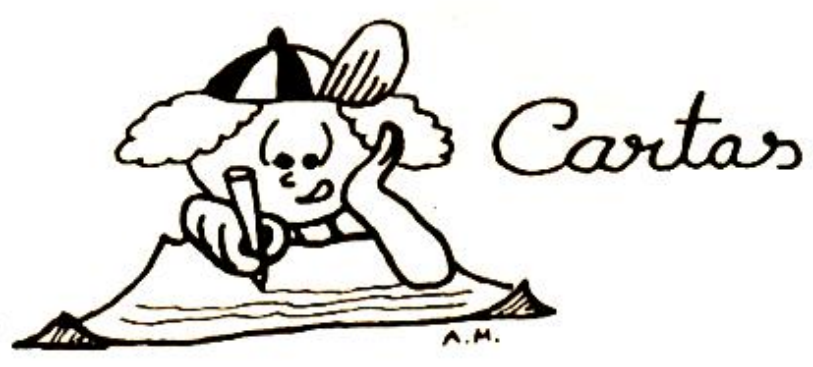

A A lesandra Chaves Pereira de 10 anos já é leitora do ESTADINHO faz tempo ela escreveu reclamando do ESTADINHO, dizendo que estácom pouco assunto, sem ciganaluca, sem receitas e charadas, nem quadrinhos do Maurício.

A lesandra, concordamos com você em alguns pontos, mas quanto aos assuntos. sempre colocamos um diferente em cada ediçáo, e o que mais falta t para nós e colaboradores. As receitas, o pessoal parou de mandar, charadas quase toda semana tem uma, nāo tem mais quadrinhos do Maurício porque estamos publicando quadrinhos de pessoal daqui mesmo. istoé, estamos dando chances pros novos desenhistas Ciganaluca volta esta semana com uma reportagem especial, e năo falamos mais do Natal, porque achamos que Natal é todos os dias, e esta ıdéia de comemorar só num dia foi idéia de alguém pra ganhar dinheiro, e pras lojas venderem mais, e o presente do ESTADINHO foi o Halley. Portanto nada melhor do que falar dele no Natal, vocé nao acha um presente diferente? Alesandra, sempre é bom recebermos criticas, portanto se você tiver alguma idéia sobre algum assunto mande para gente, tá? Um beijão e escreva sempre. 
Meninas leitoras e correspondentes de $O$ Estadinho, alfabetizadas e moradoras da região litorânea, junto a outros leitores, adultos e meninos cuja as idades variavam de 6 a 14 anos, escreveram ao suplemento por diversos motivos, mostrando, assim, que o ato de escrever “(...) é uma forma de se expor, de compartilhar experiências, tecer elos de amizade, porque, em geral se escreve cartas a alguém para explicar, justificar-se, informar, pedir, contestar, trocar sentimentos" (ROCHA, 2004, p. 68). E mesmo nas cartas trocadas entre o suplemento e seus leitores, parte do íntimo se expunha, quando os afetos eram trocados e elogios tornavamse recíprocos, permeando um imaginário de relações próximas, de amizade, de cumplicidade. Assim foi a carta de Ana Cristina Coelho:

Quero parabeniza-lo pelo último número d'O ESTADINHO em que falava sobre o primeiro1o ESTADINHO. Sobre os primeiros quadrinhos. Espero que haja muitas outras reportagens dessa, tá legal? (O ESTADINHO, 1987, p. 2).

Em resposta o suplemento afirma: “Obrigadão, Ana. E queremos cada vez mais fazer pra vocês. Se você tiver uma ideia legal de alguma reportagem é só escrever, certo? A sua história da surda está muito boa. Publicaremos logo. Aguarde" (Ibdem). Em outra carta publicada em 1/o3/1987, a relação de carinho se projeta em um dos personagens dos quadrinhos de $O$ Estadinho:

Oi ESTADINHO tudo bem? Estou mandando a minha segunda cartinha. Adorei quando a primeira foi publicada e agora vou escrever sempre para vocês, colaborando com minhas cartinhas. Tchau! Ainda adoro as estorinhas do DIGO. Meu nome é Michele Rodrigues Cabral, 10 anos. (O ESTADINHO, 1987, p. 2).

Na carta resposta, não há dificuldade para perceber que o texto foi escrito pelos editores do suplemento. Entretanto, o recado carinhoso do personagem mencionado pela menina alimenta uma aproximação entre leitores e o impresso. "Você faz uma pergunta legal e o repórter Joca Wolf vai responder o que é rock pauleira, certo? Continue escrevendo. $\mathrm{O}$ Digo mandou um beijão pra você" (Ibidem).

A carta como elo de ligação entre crianças/leitores de $O$ Estadinho, com o objetivo de fazer novas amizades e de por meio da troca de cartas 
“... compartilhar experiências, construir elos invisíveis e muitas vezes duradouros" (CUNHA, 2002, p. 184), foi incentivado pelo suplemento que na seção cartas. Foram frequentes as missivas que traziam tal intento em seu conteúdo.

Nessa variedade de intenções (CUNHA, 2002; ROCHA, 2004), sobressaíram entre os leitores de $O$ Estadinho os pedidos para publicação de desenhos e historinhas, como mostra o quadro abaixo:

Tabela 1 - Sobre as motivações para a escrita das cartas. Fonte: Acervo pessoal.

\begin{tabular}{|l|c|}
\hline \multicolumn{1}{|c|}{ Motivo da correspondência } & $\mathbf{N}^{\mathbf{0}}$ \\
\hline Pedido para publicar colaborações para o suplemento & 42 \\
\hline Pedidos diversos & 10 \\
\hline Elogios & 13 \\
\hline Agradecimento & 4 \\
\hline Informação & 2 \\
\hline Sugestões & 7 \\
\hline Críticas & 2 \\
\hline
\end{tabular}

Cartas que pediam para divulgar clubes de correspondência, tão comuns nas décadas de 1970 e 1980, e que prontamente foram atendidas pelo $O$ Estadinho, evidenciam outra temporalidade, outros hábitos, outros suportes que hoje, talvez, muitas meninas e meninos de idade entre 6 e 14 anos desconheçam. E não foram exclusividade do suplemento catarinense. Cartear-se foi também um hábito de crianças que viviam do outro lado do oceano Atlântico, como se pode comprovar por meio da seção "Llego el cartero", do suplemento MINI-YA, encartado pelo periódico YA.

Soy lectora de MINI-YA y, como a los demás, creo que les gostaria también que pusieran más hojas, porque no son suficientes para todo lo que pone MINI-YA. Creo que así podrían poner más concursos y los dibujos a tamaño um poco más grande para que se puedan distinguir los detalles. ¿Por qué no po- 
nen um Granmini-YA? También quisera comunicarme con niños de toda España y, si pude ser, de todo el mundo. Me pueden escribir mandándome fotos, contándome donde viven, como es su Pueblo, etc. Quien este interessada puede escribirme. Loly Cano, Madrid. (MINI-YA, 1976, p. 2)

Em outro impresso espanhol, ZIPIZAPE, uma página inteira dedicava-se a divulgar nome e endereço de crianças que buscavam estreitar laços de amizade por meio de cartas. A publicação das solicitações convida a pensar que a motivação para a escrita ao periódico não se dava exclusivamente para a divulgação do nome e endereço para correspondência, outras intenções estavam presentes, como enviar desenhos, fazer elogios ao periódico e mesmo, falar um pouco de si.

Figura 4 - Carta de um leitor de ZIPEZAPE. Fonte: Acervo pessoal.

Jordi es un amiguete de 10 años que nos dice en su misiva que sus aficiones preferidas son la música, nadar y leer tebeos. También nos comenta que le gustaría recibir cartas de chicos y chicas entre 10 y 16 años. Sus señas son: Jordi Ramirez. C/ San Isidro, 29, 1er. piso. Calella (Barcelona)

Rituais e protocolos que começavam no espaço privado para atingir o domínio público. "Rituais do ato de escrever" (CUNHA, 2002, p. 187), onde a presença de elementos comuns em cartas como saudações iniciais, identificação pessoal, e despedidas carinhosas faziam

se presentes na maioria das missivas publicada. Elementos muitas vezes abreviados nas comunicações de hoje (citando os e-mails), mas que foram por anos ferramentas quase que indispensável a correspondência entre pessoas, como destacam os estudos de epistolografia ligados a história da cultura escrita, sinalizados por Sieera Blás e Castillo (2008).

A publicação do nome completo, endereço e telefone de quem solicitava corresponder-se com outros leitores, trocar papeis de carta ou formar uma banda de rock foram divulgados sem qualquer restrição, mostrando que houve mudanças nessas três décadas que distanciam $O$ Estadinho dos dias atuais, em relação ao sigilo de informações de seus leitores. 
Ainda que o jornal seja um veículo de comunicação isento de imparcialidade, e levantando nesses últimos anos de existência a bandeira de que era um material para crianças e "proibido para adultos que não gostassem de crianças", $O$ Estadinho cumpria à risca com a publicação de fotos de crianças, um espaço muito mais destinado ao olhar adulto. Isso de acordo com seus editores, para garantir que o suplemento conseguisse seguir a diante (MAINGUÉ, 2014)

A independência do suplemento que interagia com seus leitores de forma aberta, esteve, parece, atrelada à coluna de fotos infantil. Entretanto, ainda que alguns textos publicassem críticas aos adultos, professores, pais, não se encontrou indícios de uma censura em relação ao suplemento, que por vezes se apresentava com certa ousadia a seus leitores, sobretudo, em seus últimos anos.

Ousadia em publicar "dicas” de como as crianças deveriam responder a seus pais, quando eles quisessem impor alguma ordem; em publicar textos reflexivos em relação à atitude de algumas professoras em classe; em incentivar a construção de projetores de cinema; em praticar esportes radicais etc. Evidências de que o suplemento acreditava no potencial de seus leitores. Tanto é que no ano de 1987, 30\% de $O$ Estadinho (que faz parte do acervo desse estudo) foi produzido por materiais (cartas, fotos, notícias) enviadas por seus leitores. Histórias, poemas, desenhos, brincadeiras, quadrinhos, receitas, foram publicadas atendendo ao pedido de muitos colaboradores, mas, também, como uma forma de garantir no suplemento um espaço que, em certa medida, representava seus leitores.

Manuseando atentamente $O$ Estadinho, percebe-se que algumas crianças escreviam com frequência para o suplemento, o que leva a crer na formação de um vínculo, entre editores e leitores. Escreviam e tinham seu material publicado, aumentando a confiança para com o suplemento e permitindo, assim, em grande medida, um contato mais próximo com tal suporte. Nesses últimos anos de publicação (1985-1987), em que a comunicação aparece como uma das coisas prioritárias no suplemento, ele se vai. Sem ao menos um exemplar que abordasse o fim ou o desaparecimento de $O$ Estadinho, resta pensar então que ele acabou não ao se deteriorar com o tempo, nem mesmo se extinguiu porque não tivesse lei- 
tores, mas que se foi precisamente quanto parecia estar no seu melhor momento.

\section{No auge, um fim... \\ Poucos resquícios, poucos indícios}

O Estadinho foi, até o momento, o suplemento infantil editado por um jornal catarinense que mais tempo circulou no estado. Acompanhou o momento político da época e em sua trajetória foi transmutando. Passando de um impresso infantil mais impessoal - haja vista que em seus primeiros anos, o conteúdo do suplemento era em grande parte fornecido pelo cartunista Maurício de Sousa -, para um suplemento mais interativo, permitindo em seus últimos anos (1984-1987), que as produções de seus leitores chegassem a ocupar até 30\% de seu material impresso.

A seção de cartas, existente desde os primeiros anos do suplemento, permitiu compreender como foram se estreitando as relações entre suplemento e seus leitores, sobretudo, a partir de 1984. O Estadinho passou a incentivar a participação de seus leitores em várias seções do suplemento, criando cada vez mais espaços para a publicação de desenhos, reportagens, poesia e até mesmo receitas.

As cartas trocadas na coluna "Cartas", evidenciaram tais participações, pois por meio delas, meninas, meninos, mesmo que incentivados por adultos expunham seus desejos e intenções naquele ato de escrita. As cartas continham palavras de carinho e em sua maioria solicitavam a publicação de algum texto, desenho, ou mesmo uma receita culinária. Respondidas e publicadas, seguiam o tom amistoso e a promessa de publicação, que por vezes dizia ao leitor que havia necessidade de esperar. Tais procedimentos permitem pensar em uma postura de tratamento honesto para com os leitores e leitoras, sem iludir a quem empregava tempo escrevendo ao suplemento e, ao mesmo tempo sinalizavam para a presença, pela escrita, de conteúdos escolares.

Durante o ano de 1987, em 17 edições pode-se observar uma aproximação entre leitores e editores do suplemento, que demostravam por 
meio de suas respostas às cartas enviadas, respeito, atenção, valorização e carinho a quem as escrevia. Em algumas respostas as cartas de seus leitores, o suplemento não se calava frente às críticas recebidas, entretanto desculpava-se quando reconhecia um erro ou tratava de esclarecer algo, quando necessário.

Indícios de que a partir de 1984, mas naquele ano - 1987 -, sobretudo, $O$ Estadinho passou a trabalhar em prol de uma infância não infantilizada. Uma compreensão de criança que precisa ser informada e esclarecida, que tem sim suas especificidades, mas que não está apartada do mundo em que vive, como bem declarou Walter Benjamin: "a criança não é nenhum Robinson, as crianças não constituem comunidade separada, mas são partes de povo e da classe que pertencem" (BENJAMIN, 1994, p. 94). E com esse pensamento, o suplemento infantil catarinense desapareceu das bancas, no momento em que talvez, pudesse ser um dos impressos que mais respeitassem e compreendessem as infâncias catarinense situação que permite considerar que no auge, deu-se um fim.

\section{Referências}

ALENCAR, P. M. G. A Revista "O Tico - Tico" e a escrita infantil em circulação no encarte "Meu Jornal": seus autores e leitores (1935-1940). Dissertação de mestrado (Educação). Universidade Estadual de Maringá, Maringá, 2015.

BENJAMIN, W. Reflexões sobre a criança, o brinquedo e a educação. $2^{\mathrm{a}}$ ed. São Paulo: Duas Cidades, Ed. 34, 2007.

BLAS, V. S. Aprender a escribir cartas. Los manuales epistolares en la España Contemporánea (1927-1945). Gijón: Trea, 2003.

CASTILLO GÓMEZ, A. La corte de Cadmo. Apuntes para una historia social de la cultura escrita. Revista de Historiografia. N. 3, p. 18-27, 2005 .

(coord.). Historia de la cultura escrita. Del Próximo Oriente Antiguo a la sociedad informatizada. Madrid: Edicciones Trea, 2002. 
CASTILLO GÓMEZ, A.; SIERRA BLAS, V. Mis primeros pasos. Alfabetización, escuela y usos cotidianos de la escritura (siglos XIX y XX). Madrid: Edicciones Trea,2008.

CHARTIER, R. A história cultural entre práticas e representações. Rio de Janeiro: Bertrand Brasil; Lisboa [Portugal]: Difel, 1990.

CHIVELET, M. La prensa infantil em España. Desde el siglo XVIII hasta nuestros días. Madrid: Fundación SM, 2009.

CUNHA, M. T. S. Mensageiro de sociabilidades: estudo sobre um jornal escolar infantil (1946-1952). In: MORGA, A. E. História, cidade e sociabilidade. Itajaí: Casa Aberta, 2011. p. 235-250.

. Por hoje é só... Cartas entre amigas. In: BASTOS, M. H. C.; CUNHA, M. T. S.; MIGNOT, A. C. V. (org.). Destinos das letras: história, educação e escrita epistolar. Passo Fundo: UPF, 2002, p. 181-204.

HAMBURGER, E. Diluindo fronteiras: a televisão e as novelas no cotidiano. In: SCHWARCZ, L. M. (org.). História da vida privada no Brasil. São Paulo: Companhia das Letras, 1998.

PEREIRA, M. Imprensa \& poder: a comunicação em Santa Catarina. Florianópolis: FCC, 1992.

PRO-CRIANÇA. Projeto Gaivota. Florianópolis: LADESC, [s.d].

ROCHA. B. T. Cartas em revistas: estratégias editorias de difusão e legitimação da Nova Escola. Dissertação de mestrado (Educação). Universidade do Estado do Rio de Janeiro, Rio de Janeiro, 2004.

RODRIGUES, M. M. Pró-criança: por entre creches, livros e canções, a busca de consensos (Santa Catarina - década de 1980). Dissertação de mestrado (Educação). Universidade Federal de Santa Catarina, Florianópolis, 2001.

SCHWARCZ, L. M.; STARLING, H. M. Brasil: uma biografia. São Paulo; Companhia das letras, 2015.

SERPA, É. C. Hoy/es el nuevo día/de un nuevo tiempo/que comenzó: modernización, cultura y poder en Brasil, 1964-1984. In: Ayer, n. 84, p. 159-182, 2011.

. Revolução, Integração e Educação: escritas para comemorar. In: SERPA, É. C. et al. (org.). Escritas da História: memória e linguagem. Goiânia: Editora da UCG, 2004, p. 65-87.

\section{Fontes impressas}

O ESTADINHO. Florianópolis, ed 28 de Maio de 1972. . Florianópolis, ed. 17 de dezembro de 1972. . Florianópolis, ed. 1 de dezembro de1974. 
. Florianópolis, ed. 12 de janeiro de 1986. . Florianópolis, ed. 23 de março de 1986. . Florianópolis, ed. 19 de outubro de 1986. . Florianópolis, ed. 30 de novembro de 1986. . Florianópolis, ed. 7 de dezembro de 1986. . Florianópolis, ed. 11 de janeiro de 1987. . Florianópolis, ed. 15 de fevereiro de 1987. . Florianópolis, ed. 22 de fevereiro de 1987. . Florianópolis, ed. 1 de março de 1987. . Florianópolis, ed. 28 de junho de 1987. . Florianópolis, ed. 5 de julho de 1987. . Florianópolis, ed. 12 de julho de 1987.

MINI-YA. Madrid, ed 12 de dezembro de 1976. ZIPIZAPE. Barcelona: Alvagraf S.A., n33, 1987.

SUPERZIPIZAPE. Barcelona: Alvagraf S.A., n101, 1987.

\section{Fontes orais}

COELHO, N. Sobre o suplemento infantil O Estadinho. Florianópolis, 21 set. 2016. Informação verbal.

MAINGUÉ, A. Sobre o suplemento infantil “O Estadinho”. Florianópolis, 2014. Entrevista concedida ao Grupo de Estudos e Pesquisas Educação e Sociedade Contemporânea (NEPESC).

VALENTE, C. Entrevista concedida ao Grupo de Estudos e Pesquisas Educação e Sociedade Contemporânea (NEPESC). Florianópolis, 2014 